DOSSIÊ EDUCAÇÃO NO BRASIL

DOI: https://doi.org/10.30749/2594-8261.v6n1p59-70

\title{
O CONTEXTO DO ENSINO REMOTO EMERGENCIAL: INCERTEZAS SOBRE A APRENDIZAGEM COM SIGNIFICADO SOCIAL
}

\author{
THE CONTEXT OF EMERGENCY REMOTE TEACHING: \\ UNCERTAINTIES ON LEARNING WITH SOCIAL MEANING
}

\author{
Janille da Costa Pinto ${ }^{1}$ \\ Rosemary Lopes Soares da Silva²
}

\begin{abstract}
Resumo: $O$ presente artigo reflete sobre a efetividade do Ensino Remoto Emergencial no corrente ano Continuum 2020/2021 no sentido de oportunizar a aprendizagem com significado social, um dos princípios defendidos por Paulo Freire, para os/as estudantes das escolas públicas estaduais da Bahia. Para tanto, o foco deste estudo é identificar como está sendo planejado e concretizado o processo de ensino nas escolas estaduais da Bahia durante o período pandêmico de 2021. Verificar quais recursos e estratégias pedagógicas estão sendo adotadas para favorecer a aprendizagem com significado social para os/as estudantes. Bem como, discutir se a educação ofertada promove a formação emancipatória e crítica para a atuação na sociedade, como defende Paulo Freire. A metodologia está baseada na revisão da literatura a partir dos referenciais teóricos de Freire $(1996 ; 1987)$ para a análise documental das legislações estudadas sobre a educação escolar qualificada como Ensino Remoto Emergencial. Os resultados deste estudo apontam para a incerteza acerca da efetividade do ensino que favoreça a aprendizagem com significado social visando a emancipação dos estudantes, crianças, jovens, adultos, homens e mulheres, que são os/as estudantes da educação básica, por considerar que, as gritantes desigualdades econômicas e sociais no Brasil e na Bahia comprometem o pleno acesso dos sujeitos nesta forma de oferta educacional.
\end{abstract}

Palavras-Chave: Ensino Remoto Emergencial. Aprendizagem. Pandemia.

Abstract: This article presents a reflection on the effectiveness of Emergency Remote Teaching in the current year Continuum 2020/2021 in terms of providing opportunities for learning with social meaning (one of the principles defended by Paulo Freire) for students in state public schools in Bahia. Therefore, the focus of this study is to identify how the teaching process in state schools in Bahia is being

\footnotetext{
${ }^{1}$ Mestrado em Ciências da Educação, Núcleo Territorial de Educação Litoral Sul da Bahia (NTE 05), Grupo de Estudos e Pesquisas Movimentos Sociais, Diversidade e Educação do Campo GEPEMDECC do CEPECH/DCIE/UESC).

${ }^{2}$ Doutorado em Políticas Públicas e Formação Humana, Secretaria da Educação do Estado da Bahia, Grupo de Pesquisa- Grupo de Estudos, Pesquisas e Experimentações Educacionais - GEPEE.
}

Revista Lex Cult, Rio de Janeiro, v. 6, n. 1, p. 59-70, jan./abr. 2022. 
planned and implemented during the pandemic period of 2021. It verifies which resources and pedagogical strategies are being adopted to favor learning with social meaning for them( as) students. As well as discussing whether the education offered promotes emancipatory and critical training for students to act in society as advocated by Paulo Freire. The methodology is based on the literature review of theoretical references of Freire $(1996 ; 1987)$ for the documental analysis of the studied legislation about this form of school education qualified as Emergency Remote Teaching. The results of this study point to the uncertainty about the effectiveness of teaching that favors learning with social meaning aiming at the emancipation of students, children, youth, adults, men and women students of basic education, since the glaring economic and social inequalities in Brazil and in Bahia compromise the full access of the subjects to this form of educational offer.

Keywords: Emergency Remote Learning. Learning. Pandemic.

Recebido em: 13/10/2021 Aceito para publicação em: 10/11/2021 
O CONTEXTO DO ENSINO REMOTO

EMERGENCIAL: INCERTEZAS SOBRE A

APRENDIZAGEM COM SIGNIFICADO SOCIAL
Janille da Costa Pinto Rosemary Lopes Soares da Silva

\section{INTRODUÇÃO}

A aprendizagem com significado social defendida por Paulo Freire está intrinsecamente ligada à indissociabilidade da construção dos processos de aprendizagem com o processo de politização que se relaciona com a atuação do sujeito no mundo, isto é, suas relações e inter-relações na sociedade e instituições (formais e/ou não formais), em que vivemos, pois o ser humano é um sujeito político e a educação é um ato político.

Desse modo, entendemos que a educação não é neutra, ela vem carregada de significados que influenciam na vida do ser humano. Segundo Freire (1996, p.21) "ensinar não é transferir conhecimento, mas criar as possibilidades para a sua própria produção ou a sua construção". Assim, é por meio da educação que conseguimos continuamente construir e reconstruir significados de uma dada realidade, objetos, bem como das nossas ações no ambiente em que vivemos, que por sua vez são movidas pelas crenças e valores socialmente construídos.

Mediante esse entendimento, precisamos reportar para a realidade pandêmica que o mundo vive desde o ano de 2019. Em especial na Bahia desde o dia 06 de março de 2020, quando foi confirmado pela Secretaria Estadual da Saúde da Bahia (SESAB) a primeira pessoa acometida pela Infecção Humana no contexto da pandemia do vírus SARS COV-2 (Covid-19), ou, o novo Coronavírus (2019), que ocasiona a doença COVID-19. Justamente porque, nesse momento, a educação passa por uma grande ruptura da práxis pedagógica, pois as aulas presenciais tiveram que ser suspensas como uma das medidas para conter a propagação do vírus devido a necessidade de manter o distanciamento social. Cabe destacar que a práxis para Freire (1987, p. 42) "é a reflexão e ação dos homens sobre o mundo para transformá-lo. Sem ela, é impossível superação da contradição opressor oprimido". 
O CONTEXTO DO ENSINO REMOTO

EMERGENCIAL: INCERTEZAS SOBRE A

APRENDIZAGEM COM SIGNIFICADO SOCIAL
Janille da Costa Pinto Rosemary Lopes Soares da Silva

Em março de 2021, a Rede Estadual de Educação da Bahia retorna as aulas no formato não presencial, Momento em que a Secretaria Estadual de Educação da Bahia (SEC-BA), apresentou a comunidade diversos documentos norteadores e legisladores para efetivar a educação em meio a pandemia, como a portaria $n^{\circ} 711$ (2021), que estabelece normas, procedimentos e cronograma para a renovação de matrícula escolar, transferência e matrícula de novos estudantes para cursar o ano letivo continuum 2020/2021. E o Protocolo da Educação Ano Letivo 2020-2021, dentre outros documentos.

Mediante esse novo cenário educacional baiano e conscientes dos preceitos freirianos para educação, buscamos identificar como está sendo planejado e concretizado o processo de ensino e aprendizagem nas escolas estaduais da Bahia durante o período pandêmico de 2021. Quais recursos e estratégias pedagógicas foram adotados para favorecer a aprendizagem com significado social para os/as estudantes. Bem como problematizar acerca da educação ofertada, se promove a formação emancipatória e crítica para os/as estudantes atuarem na sociedade como defende Paulo Freire. Justamente porque estamos vivenciando um período pandêmico que trouxe consigo inúmeras mudanças nas formas de se relacionar, conviver em sociedade, além de expor várias mazelas que tem como determinantes sociais a extrema desigualdade econômica e social no Brasil, e em especial, evidenciando que o povo baiano representa o estado brasileiro com expressiva desigualdade social, jogando luz sobre questões que dizem respeito a sobrevivência em condições tão adversas e ao mesmo tempo como se manter estudando nestas condições.

Dessa forma, nos guiamos por uma questão de estudo que se refere a discutir se o ensino remoto na educação estadual da Bahia favorece a aprendizagem com significado social defendido por Paulo Freire. Visto que o referido autor destaca que é necessário a indissociabilidade entre a construção dos processos de aprendizagem com o processo de politização dos sujeito, pois o homem não se 
O CONTEXTO DO ENSINO REMOTO

EMERGENCIAL: INCERTEZAS SOBRE A

APRENDIZAGEM COM SIGNIFICADO SOCIAL
Janille da Costa Pinto Rosemary Lopes Soares da Silva

encontra isolado da realidade, nem a realidade está separada do homem, só podemos compreendê-los nas relações homens-mundo (FREIRE, 1987).

\section{A EDUCAÇÃO NA BAHIA E A APRENDIZAGEM COM SIGNIFICADO SOCIAL NO CONTEXTO PANDÊMICO 2021}

Ao longo do ano de 2020, enquanto as aulas estavam suspensas, os diversos órgãos que regulamentam a educação no nível nacional e estadual, como o Ministério da Educação (MEC), Conselho Nacional de Educação (CNE), Conselho Estadual de Educação da Bahia (CEE) e a Secretaria Estadual de Educação da Bahia (SEC-BA) construíram e lou adequaram leis, resoluções e documentos orientadores para atender as rotinas educativas às novas demandas e restrições provocadas pela pandemia.

Dentre essas legislações podemos destacar em âmbito nacional a lei $\mathrm{n}^{\circ}$ 14.040, de 18 de agosto de 2020, que estabelece normas educacionais excepcionais a serem adotadas durante o estado de calamidade pública e a Resolução CNE/CP $\mathrm{n}^{\circ}$ 2, de 10 de dezembro de 2020, que institui as Diretrizes Nacionais Orientadoras para a implementação dos dispositivos da Lei $n^{\circ}$ 14.040. Em âmbito estadual, destacamos a Portaria $n^{\circ} 711$ (2021), que estabelece normas, procedimentos e cronograma para a renovação de matrícula escolar, transferência e matrícula de novos estudantes para cursar o ano letivo continuum 2020/2021.

Considerando a restrição do formato presencial, atendendo aos protocolos internacionais, e pelo imperativo da necessidade de mudança das práticas educativas, "este é um pensar que percebe a realidade como processo, que capta em constante devenir e não como algo estático. [...] Banha-se permanentemente de temporalidade cujos riscos não teme" (FREIRE,1987, p.47). Percebemos que, no que se refere aos documentos normativos, observamos que os mesmos foram construídos levando-se em consideração as heterogeneidades dos territórios de identidades e dos lugares em que estão as unidades escolares, ao destacar as 
O CONTEXTO DO ENSINO REMOTO

EMERGENCIAL: INCERTEZAS SOBRE A

APRENDIZAGEM COM SIGNIFICADO SOCIAL
Janille da Costa Pinto Rosemary Lopes Soares da Silva

realidades locais na relação com a efetividade do processo pedagógico, ressalta a necessária adoção de protocolos sanitários para que as escolas consigam executar as novas rotinas, assim como a aquisição de bens e serviços visando a realização de intervenções na infraestrutura física e tecnológica das escolas. Como uma forma de envolver os sujeitos educativos para desenvolver suas capacidades de aprender, não apenas para adaptar "mas sobretudo para transformar a realidade, para nela intervir" (FREIRE, 1996, p. 69).

Dos documentos expedidos pela SEC-BA (2021), o planejamento do retorno escolar está pautado em quatro diretrizes, a saber: i) Garantia da matrícula - por meio da matrícula automática dos estudantes. ii) Adoção do continuum curricular - $O$ ano letivo de 2021 associará o percurso curricular programado para dois anos letivos, 2020 e 2021, de forma gradativa. iii)Retorno em fases -conciliando o tempo presencial na unidade escolar (Tempo Escola) e o tempo não presencial em domicílio (Tempo Casa). iiii) Criação do Comitê Gestor da Escola - Composto pelo Colegiado Escolar, para acompanhar o cumprimento dos protocolos sanitários, mapear possíveis novos casos e monitorar a frequência dos estudantes.

Mediante essas diretrizes, notamos que as unidades escolares se preparam para um futuro de incertezas na educação pela necessidade de profundas mudanças na organização do trabalho pedagógico e na realização das aulas em razão da pandemia. Entretanto, Freire (1996, p. 79) já nos advertiu que é preciso que tenhamos resistência no que nos preserva vivos, e sobre a necessidade de programar nossa ação político-pedagógica. Diante dos desafios do Ensino Remoto Emergencial, e das improvisações, o receituário amplamente difundido para que "não seja mera transposição das aulas presenciais para o ambiente online", se tornou realidade. Embora conscientes de que esse tipo de ensino "requer adaptações de planejamentos didáticos, estratégias, metodologias, recursos educacionais, no sentido de apoiar os estudantes na construção de percursos ativos de aprendizagem" (OLIVEIRA, 2020, p. 12). 
Observamos que na realidade das unidades escolares atentas para o reconhecimento da heterogeneidade (econômica, cultural, sanitária, social, financeiras, dentre outras), conforme defendida por Freire, na educação dialógica e na problematização das questões sociais, pois ensinar é inserir-se na história: não é só estar na sala de aula, mas num imaginário político mais amplo (GADOTTI, 1999, p. 10), a efetividade das atividades escolares, desde o dia 15 de março, quando iniciou a fase do Ensino Remoto do ano continuum curricular 2020-2021, proporciona inúmeros desafios para assegurar a qualidade do ensino público ofertado, que vão desde o acesso às aulas remotas, acesso a materiais didáticos, acesso a segurança alimentar por meio da merenda escolar, tendo em vista que para uma minoria dos estudantes da rede pública esta se constitui como a primeira refeição do dia ou mesmo a principal refeição do dia.

Neste contexto pandêmico cabe problematizar o papel da escola pública no Brasil frente as extremas desigualdades econômicas e sociais, como destaca Gadotti (2007, p. 50), "a escola pública do futuro, numa visão cidadã freireana, tem por objetivo oferecer possibilidades concretas de libertação para todos", justamente porque Paulo Freire defendia uma escola pública que seja da maioria dos cidadãos (ãs) que só podem contar com ela. A educação precisa ser compreendida ao mesmo tempo "como um ato político, como um ato de conhecimento e como um ato criador" (GADOTTI, 1996, p.80).

O modus operandi da educação básica de nível médio na Bahia acontece pela utilização das Tecnologias da Informação e Comunicação - TIC, especificamente, as ferramentas disponibilizadas via plataforma da Google, por meio do acesso ao Google Classroom, Google Meet, drive, dentre outras ferramentas para acessar materiais de estudos produzidos pela SEC-Ba, tais como, as trilhas de estudo, pílulas de aprendizagem, roteiros de estudos, cadernos de aprendizagem, chat class, dentre outros. 
Dentre essas TIC, fica evidente que a mais utilizada e acessível aos(às) alunos/as e professores/as é o celular, devido a presença do aplicativo WhatsApp. É por meio desse aplicativo que a mediação pedagógica e o diálogo entre aluno(a) e professor/a ocorre, que para Freire (1987), a ausência deste diálogo, leva a um autoritarismo no processo educativo. Ademais, através desse aplicativo são enviados materiais de estudo e realização de aulas online por meio de vídeo chamada em grupo. Assim, notamos que apesar das restrições das aulas presenciais, o processo de mediação e diálogo está ocorrendo, rompendo com os sistemas verticais característicos da educação bancária e fundamenta-se na perspectiva do diálogo (FREIRE,1987), pois segundo Freire (1987), o educador não é mais apenas o que educa, mas sim o que quando educa é educado.

Além disso, verificamos que as unidades escolares estão utilizando as redes sociais como YouTube para aulas online, lives, seminários e reuniões. O Facebook e Instagram para exposição de materiais produzidos e lives, como sendo as possibilidades que se colocaram para a educação. Em outros momentos históricos essa mediação tecnológica foi destacada por Freire (1996), como: "não a divinizo, de um lado, nem a diabolizo, de outro. Por isso mesmo sempre estive em paz para lidar com ela" (FREIRE, 1996, p.87).

Vale ressaltar que os planejamentos escolares em contexto pandêmico se realizam por mediações tecnológicas na forma de aulas online, isto é, síncrona, onde "demandam que docentes e discentes estejam conectados em tempo real, de forma simultânea, com apoio de tecnologias e ferramentas que sejam capazes de manter as interações on-line" (OLIVEIRA et al, 2020, p. 26). Como também estão mantendo interações assíncronas, em que "apresentam maior flexibilidade temporal, pois não demandam que docentes e discentes estejam conectados em tempo real, de modo simultâneo" (OLIVEIRA et al, 2020, p. 29). Como forma de fazer chegar aos destinatários o conteúdo programático a partir das relações educador e educando, mediatizados nas relações homem-mundo (FREIRE, 1987). 
Levando em consideração o planejamento, organização e o início da execução do ensino remoto ofertado pela SEC-BA para atender as demandas impostas pela pandemia da COVID 19, notamos que embora as equipes escolares estejam comprometidas e engajadas para a realização do ensino remoto emergencial, os condicionantes históricos e sociais das desigualdades existentes no Brasil e na Bahia comprometem a qualidade da educação ofertada.

Desse modo, notamos que as mediações pedagógicas durante o Ensino Remoto, ocorrem entre improvisos e planejamentos considerando os inúmeros desafios encontrados ao longo do percurso, como a falta de acesso a equipamentos adequados, a falta de acesso à internet que prejudica o diálogo contínuo do(a) professor(a) e os(as) estudantes, bem como a disponibilidade de materiais. Apesar de termos consciência de que "aprender não é memorizar o perfil do conteúdo transferido no discurso vertical do professor" (FREIRE, 1996, p. 118).

Portanto, entendemos que a educação na Rede de Ensino analisada, expressa que a relação entre a tríade: a forma, o conteúdo e destinatário a partir do qual se pretende assegurar a aprendizagem com significado social, que ao confrontar-se com as condições materiais reais do estudante como ser social, histórico, frente a educação ofertada em contexto pandêmico, intermediado pelas tecnologias da comunicação, não assegura uma educação para a formação do ser pensante, comunicante, transformador, criador, realizador de sonhos (FREIRE, 1996), capaz de realizar leitura de mundo para posteriormente interferir e transformar a sua realidade.

\section{CONSIDERAÇÕES FINAIS}

Ao final da análise aqui empreendida e embasada nos pressupostos da educação freiriana, ao refletir sobre os processos educativos de forma crítica relacionando-os com as lutas e os anseios da sociedade na perspectiva da inclusão, 
estamos conscientes de que "a realidade social não existe por acaso, nem se transforma por acaso" (FREIRE, 1987, p .41).

Notamos que no intuito, do Ensino Remoto no corrente ano Continuum 2020/2021, na Rede Estadual da Bahia, de buscar oportunizar a aprendizagem com significado social (um dos princípios defendidos por Paulo Freire) para os/as estudantes das escolas públicas estaduais da Bahia, operou-se adequações no ensino e no currículo para atender as heterogeneidades dos/as profissionais da educação, alunos/as, unidades escolares e comunidades. Para assim, verem significados no que estão estudando nas aulas online e materiais impressos. Expressando em documentos a prerrogativa para o diálogo horizontal, o respeito ao conhecimento prévio dos/as alunos/as, sua cultura, seu papel social, e a realidade sanitária de cada localidade.

Identificamos que o Ensino para o período da pandemia planejado em três fases: ensino remoto, híbrido e presencial, em que os/as estudantes terão acesso às atividades curriculares mediadas por recursos tecnológicos digitais ou não digitais, em momentos síncronos e assíncronos, por meio dos dispositivos tecnológicos e pedagógicos disponibilizados pela empresa Google em parceria com a SEC-BA como google meet \& google classroom. Além das redes sociais como Facebook e Instagram, e aplicativos de comunicação como o WhatsApp, em que $85 \%$ do acesso é realizado através de aparelhos celulares, se colocaram como imperativos e como "soluções únicas e as mais viáveis" para as redes públicas em especial a da Bahia, pela plena adoção de tais medidas.

Por fim, percebemos que a educação que promove a formação emancipatória e crítica para os(as) estudantes atuarem na sociedade, como defende Paulo Freire, neste contexto pandêmico, ver-se ameaçada, haja vista a necessidade de serem realizadas adequações curriculares além das restrições ao acesso às aulas pelas ausências das condições materiais reais da maioria dos estudantes baianos. 
O CONTEXTO DO ENSINO REMOTO

EMERGENCIAL: INCERTEZAS SOBRE A

APRENDIZAGEM COM SIGNIFICADO SOCIAL
Janille da Costa Pinto

Rosemary Lopes Soares da Silva

\section{REFERÊNCIAS}

BAHIA. Conselho Estadual de Educação. Secretaria de Estado de Educação da Bahia. Resolução CEE n $^{\circ}$ 27, de 25 de março de 2020. Orienta as instituições integrantes do Sistema Estadual de Ensino sobre o desenvolvimento das atividades curriculares, em regime especial, enquanto permanecerem os atos decorrentes do Decreto Estadual $n^{\circ} .19 .529$, de 16 de março de 2020, que estabelece as medidas temporárias para o enfrentamento de Emergência em Saúde Pública de Importância Internacional - ESPIN, para fins de prevenção e enfrentamento à COVID19.

Salvador: CEE - BA. Disponível em:

http://www.conselhodeeducacao.ba.gov.br/arquivos/File/homologadares272020.pdf. Acesso em: 04 jun. 2021.

BAHIA. Conselho Estadual de Educação. Secretaria de Estado de Educação da Bahia. Resolução CEE n. ${ }^{\circ}$ 50, de 09 de novembro de 2020. Normatiza procedimentos para a integralização da carga horária mínima do ano letivo afetado pelo estado de calamidade pública e para a reorganização do calendário escolar do ano letivo de 2020, à luz da Lei Federal N. ${ }^{\circ}$ 14.040, de 18 de agosto de 2020.

Salvador: CEE - BA. Disponível em:

http://www.conselhodeeducacao.ba.gov.br/arquivos/File/Resolucao_50_e_Parecer_9 9.pdf. Acesso em: 10 mar. 2021.

BAHIA. Secretaria de Estado de Educação da Bahia. Portaria $\mathbf{n}^{\circ} \mathbf{7 1 1}$, de 10 de março de 2021. Estabelece normas, procedimentos e cronograma para a renovação de matrícula escolar, de transferência de estudantes entre escolas da Rede Pública Estadual de Ensino e de matrícula escolar de estudantes oriundos das Redes Municipais de Ensino, bem como para candidatos à Educação Básica nas Unidades Escolares da Rede Pública Estadual de Ensino e Conveniadas, referentes ao ano letivo continuum 2020/2021. Salvador: Secretaria de Estado de Educação da Bahia, 10 mar. 2021. Disponível em:

http://www.educacao.ba.gov.br/midias/documentos/portaria-n\%C2\%BA-7112021.

Acesso em: 04 jun. 2021.

BRASIL. Lei $\mathbf{n}^{\circ} \mathbf{1 4 . 0 4 0}$, de 18 de agosto de 2020. Estabelece normas educacionais excepcionais a serem adotadas durante o estado de calamidade pública reconhecido pelo Decreto Legislativo $n^{\circ} 6$, de 20 de março de 2020; e altera a Lei $n^{\circ}$ 11.947, de 16 de junho de 2009. Brasília, DF: Presidência da República, [2020]. Disponível em: http://www.planalto.gov. br/ccivil_03/_ato2019-2022/2020/lei/ L1 4040.htm. Acesso em: 10 mar. 2021.

BRASIL. Ministério da Educação. Conselho Nacional de Educação. Resolução CNE/CP n 2, de 10 de dezembro de 2020. Institui diretrizes nacionais orientadoras 
para a implementação dos dispositivos da lei $n^{0} 14.040$, de 18 de agosto de 2020, que estabelece normas educacionais excepcionais a serem adotadas pelos sistemas de ensino, instituições e redes escolares, públicas, privadas, comunitárias e confessionais, durante o Estado de Calamidade reconhecido pelo Decreto Legislativo $n^{\circ}$ 6, de 20 de março de 2020. Brasília, DF: Ministério da Educação, 11 dez. 2020. Disponível em:

https://www.In.Gov.Br/En/Web/Dou/-/Resolucao-Cne/Cp-N-2-De-10-De-Dezembro-D e-2020-293526006. Acesso Em: 10 Mar. 2021.

FREIRE, Paulo. Pedagogia da Autonomia: saberes necessários à prática educativa. São Paulo: Paz e terra,1996.

FREIRE, Paulo. Pedagogia do oprimido. 39. ed. Rio de Janeiro: Paz e Terra, 1987. GADOTTI, Moacir. Escola Cidadã. São Paulo: Cortez, 1999.

GADOTTI, Moacir. Paulo Freire: uma bibliografia. São Paulo: Cortez,1996.

GADOTTI, Moacir. A escola e o professor: Paulo Freire e a paixão de ensinar. São Paulo: Publisher Brasil, 2007.

OLIVEIRA, Maria do Socorro de L. et al. Diálogos com docentes sobre ensino remoto e planejamento didático. Recife: EDUFRPE, 2020. Disponível em: http://www.decon.ufrpe.br/sites/ww4.deinfo.ufrpe.br/files/di\%C3\%A1logo.com_.docen tes.ensino.remoto.planejamento.did\%C3\%A1tico.pdf. Acesso em: 18 mar.2021. 